\title{
Antioxidant Activity and Anti-inflammatory Effect of Extracts from Paulownia tomentosa in LPS-stimulated RAW264.7 macrophage cells
}

\author{
Na-Young Jo ${ }^{1}$, Ki-Tae $\mathrm{Kim}^{2 *}$ \\ ${ }^{1}$ Dept. of Diagnosics, College of Korean Medicine, Semyung University \\ ${ }^{2}$ Dept. of Internal Medicine, College of Korean Medicine, Semyung University
}

In this study, we investigated the antioxidant and anti-inflammatory effect of the Paulownia tomentosa extracts (PTE). The total polyphenol and flavonoid contents of PTE were $148.98 \pm 1.84 \mathrm{mg} \mathrm{GAE} / \mathrm{g}$ extract, and $115.33 \pm 4.16 \mathrm{mg} \mathrm{CE} / \mathrm{g}$ extract, respectively. The PTE showed that strong antioxidant activity via -diphenyl-2-picrylhydrazyl (DPPH) radical scavenging activity, ABTS radical scavenging activity and FRAP assay. The anti-inflammatory activity was evaluated on lipopolysaccharide (LPS)-stimulated RAW264.7 cells. PTE remarkably reduced protein expression of inducible nitric oxide (iNOS), resulting in inhibition of production of nitric oxide (NO). Additionally, pre-treatment of PTE significantly suppressed the production of inflammatory cytokines, such as tumor necrosis factor- $\alpha$ (TNF- $\alpha$ ) and interleukin-6 (IL-6). Moreover, PTE significantly attenuated LPS-induced IkappaB (I $\kappa$ B) degradation and suppressed nuclear factor kappa B $(\mathrm{NF}-\kappa \mathrm{B})$ nuclear translocation in macrophages. The PTE showed high antioxidant and anti-inflammatory activity. These data suggest that PTE has pharmacological activity and may be useful for the development of anti-inflammatory agents.

$\overline{\text { Key Words }}$ : Paulownia tomentosa, Anti-inflammatory effect, Nitric oxide (NO), RAW264.7 cells

\section{Introduction}

Cells of tissues and organs are constantly exposed to oxidative stress and free radicals every day. Normal cells respond by using antioxidant enzymes such as glutathione (GSH), vitamins $\mathrm{C}$ and $\mathrm{E}$, catalase, superoxide dismutase. Sophisticated DNA repair mechanisms are also used ${ }^{1)}$.

If the balance between the production of free radicals and the defense mechanisms of cells is broken, the human body is exposed to oxidative stress. Oxidative stress causes chronic diseases such as cancer, diabetes, neurodegenerative diseases and cardiovascular disease. To overcome this, many studies have been done on the antioxidant effects of natural products. Long-term intake of antioxidant-rich foods may delay or avoid the development of related diseases ${ }^{2}$.

According to Brewer's research ${ }^{3)}$, antioxidants are generally thought to be more superior to natural antioxidants than synthetic antioxidants because they are proportional to the number of hydroxyl $(\mathrm{OH})$ groups present in the aromatic rings, therefore research continues to find new

- Received : 19 November 2019

- Accepted : 29 November 2019

- Correspondence to : Ki-Tae Kim

Dept. of Acupuncture \& Moxibustion Medicine, Je-Cheon Hospital of Traditional Korean Medicine, Semyung University Semyungro 66, sinwoul-dong, jecheon city, chungbuk, 27136, Republic of Korea

Tel : +82-43-649-1874, Fax : +82-43-645-1382, E-mail : vivies@dju.ac.kr 
natural products with antioxidant properties.

Continuous exposure of cells to oxidative stress increases the expression of genes that cause degenerative diseases, leading to chronic inflammatory responses.

Inflammatory responses are involved in the production and regulation of pro-inflammatory cytokines such as nitric oxide, prostaglandins and TNF- $\alpha$ in macrophages. NO is an inflammatory mediator and is produced by nitric oxide synthases(NOS). Inducible nitric oxide synthase (iNOS) stimulates the inflammatory response by producing $\mathrm{NO}$ in macrophages involved in the inflammatory response ${ }^{4)}$. Cyclooxygenase-2(COX-2) also stimulates prostaglandin biosynthesis as well as NO production. The inflammatory response also acts as a normal defense mechanism of the human body, but if the inflammatory response becomes chronic, it can cause inflammatory diseases such as rheumatoid arthritis, arteriosclerosis, gastritis and asthma ${ }^{5)}$.

Paulownia tomentosa is a deciduous tree belonging to the paulownia family distributed in Korea, China, and Japan. It is about $15 \mathrm{~m}$ high, its branches starve and spread, and the bark is grayish brown with hairs on young branches. Paulownia tomentosa can be used to treat deodorants, hair growth, gonorrhea and bruises ${ }^{6}$. Paulownia tomentosa is known to contain catapol, syringin, aucabin, caniferin, actcoside, paulownin, sesamin, (+)-pipertol and the like. Pharmacological studies have also reported antimicrobial activity against Staphlococcus aureus and Pseudomonas aeruginosa $^{7,8)}$.

Although methanol, ethanol and water soluble extracts of Paulownia tomentosa fruit were compared with antioxidant activity ${ }^{9)}$, the antioxidant and anti-inflammatory effects of Paulownia tomentosa branches have not been studied.

In this study, the antioxidant and anti-inflammatory activity of Paulownia tomentosa was analyzed by using ethanol extract of Paulownia tomentosa, and the anti-inflammatory activity was analyzed through RAW264.7 macrophages induced by LPS.

\section{Materials and methods}

\section{Reagent}

The domestic paulownia tree used in this experiment was purchased from Samhong Construction Co., Ltd. (Seoul).

Reagents such as Folin-Ciocalteu's reagent, ferric chloride $\left(\mathrm{FeCl}_{3}\right)$, 1,1-diphenyl-2-picrylhydrazyl (DPPH) 2,2'-azino-bis(3-ethylbenzothiazoline-6sulfonic acid)(ABTS), potassium persulfate, 4,6-tripyridyl-S-triazine (TPTZ) used in the experiment were Sigma-Aldrich Ltd. (St. Louis, MO, USA), all other reagents used were express.

\section{Extraction of samples}

The paulownia sample used in this experiment was extracted using ethanol.

$1.0 \mathrm{~g}$ of ethanol was added to $100 \mathrm{~g}$ of a real paulownia sample, extracted three times at room temperature for 24 hours, filtered through filter paper(No. 41, Whatman, Maidstone, England), and concentrated by rotary vacuum evaporator (EYELA, Tokyo, Japan) and lyophilized.

Extracted paulownia samples were stored frozen and used in the experiment.

\section{Total Polyphenol Content Determination}

Total polyphenol content was determined by slightly modifying the method of Singleton and 
Rossi ${ }^{10)}$.

To $200 \mu \mathrm{l}$ of paulownia extract, add $1.0 \mathrm{~N}$ Folin-Ciocalteau Reagent and $20 \% \quad \mathrm{Na}_{2} \mathrm{CO}_{3}$ solution in $1.0 \mathrm{~mL}$ each. The reaction was carried out at room temperature for 30 minutes. And then, the absorbance was measured at $700 \mathrm{~nm}$ using a microplate spectrophotometer(Thermo Scientific Multiskan GO, Thermo Fisher Scientific, Ratastie, FINLAND).

Gallic acid was used as a standard to calculate the total polyphenol content of the paulownia extract and expressed as gallic acid equivalents (mg GAE /g extract).

\section{Total Flavonoid Content Determination}

Total flavonoid content slightly modified the method of Jia et $\mathrm{al}^{11)}$.

$1.25 \mathrm{~mL}$ of distilled water was mixed with $0.25 \mathrm{~mL}$ of paulownia extract and $75 \mu \mathrm{L}$ of $5 \%$ sodium nitrite was added and allowed to react at room temperature for 5 minutes.

After adding $0.15 \mathrm{~mL}$ of $10 \%$ aluminum chloride and reacting for 6 minutes at room temperature, $0.5 \mathrm{~mL}$ of $1.0 \mathrm{M}$ sodium hydroxide and $275 \mu \mathrm{L}$ of distilled water were added and mixed in order, and then the absorbance was measured at $510 \mathrm{~nm}$. Total flavonoid content of paulownia extract was calculated using catechin as standard and expressed as catechin equivalents (mg CE/g extract).

\section{DPPH Radical Scavenging Activity by Electron Spin Resonance(ESR)}

DPPH radical scavenging ability followed the measurements performed by Lee et $\mathrm{al}^{12)}$. $60 \mu \mathrm{L}$ dissolved in methanol and $60 \mu \mathrm{L}$ of DPPH and $60 \mu \mathrm{L}$ of various concentrations of the sample were mixed well and allowed to react at room temperature for 2 minutes. And then, It was transferred to a capillary tube and measured with an ESR spectrometer(Jeol Co.Ltd., Tokyo, Japan). The measurement conditions were central field: $3475 \mathrm{G}$, modulation frequency: $100 \mathrm{kHz}$, modulation amplitude: $2 \mathrm{G}$, microwave power: $5 \mathrm{~mW}$, gain: $6.3 \times 105$, and temperature: $298 \mathrm{~K}$.

\section{Total Antioxidant Activity Using ABTS Radicals}

Antioxidant activity using ABTS radical was slightly modified by the ABTS cation decolorization assay method ${ }^{13)}$. $7.4 \mathrm{mM}$ ABTS solution and 2.4 $\mathrm{mM}$ potassium persulfate were mixed and reacted in the dark for 12-16 hours to generate ABTS radicals. The absorbance of the generated ABTS radicals was diluted with distilled water to 1.5 at $734 \mathrm{~nm}, 1.0 \mathrm{~mL}$ was taken, $100 \mu \mathrm{L}$ of the sample was added, and reacted at room temperature for 10 minutes to measure absorbance at $734 \mathrm{~nm}$.

The results were expressed as $\mathrm{mM}$ Trolox equivalent/mg extract using Trolox as standard.

\section{Determination of Total Antioxidant Capacity Using Ferric reducing antioxidant power (FRAP)}

FRAP measurements were taken by Benzie and Strain $^{14)}$.

FRAP reagent was prepared by mixing 300 $\mathrm{mM}$ acetate buffer (pH 3.6), $10 \mathrm{mM}$ TPTZ dissolved in $40 \mathrm{mM} \mathrm{HCl}$, and $20 \mathrm{mM} \mathrm{FeCl} 3.6 \mathrm{H}$ $2 \mathrm{O}$ at a ratio of $10: 1: 1(\mathrm{v} / \mathrm{v} / \mathrm{v}) .0 .15 \mathrm{~mL}$ of sample and $3.0 \mathrm{~mL}$ of FRAP reagent were mixed and reacted at $37{ }^{\circ} \mathrm{C}$ for 5 minutes, and the absorbance was measured at $593 \mathrm{~nm}$.

The results were expressed as $\mathrm{mM} \mathrm{FeSO}_{4}$ 
equivalent/mg extract using $\mathrm{FeSO}_{4}$ as standard.

\section{Cell culture}

Macrophages (RAW264.7) were cultured in Dulbecco's modified eagle medium (DMEM) medium containing $10 \%$ inactivated fetal bovine serum (FBS) and 1.0\% penicillin-streptomycin at $37{ }^{\circ} \mathrm{C}$ and $5 \% \mathrm{CO}_{2}$.

\section{Cytotoxicity measurement}

To evaluate the cytotoxicity of paulownia extract on macrophages, the survival rate of the cells was measured by slightly modifying the method of Berridge and Tan ${ }^{15}$.

RAW 264.7 cells were seeded in 96-well plates at a concentration of $2 \times 10^{4}$ cells/well and precultured for 20 hours. Then paulownia extract was added by concentration $(25,50,100,200 \mu$ $\mathrm{g} / \mathrm{mL}$ ) and incubated for 24 hours.

After 2 hours after adding $0.2 \mathrm{mg} / \mathrm{mL}$ MTT solution, the supernatant was discarded, and 150 $\mu \mathrm{L}$ of dimethyl sulfoxide (DMSO) was added to dissolve the generated formazan, and the absorbance was measured at $540 \mathrm{~nm}$.

Cell viability was calculated by the following method.

Cell viability $(\%$ of control $)=$

Sample Treatment Group Absorbance/Control Group absorbance $\times 100$

\section{Nitric oxide production measurement}

In order to confirm the anti-inflammatory effect of paulownia extract on the inflammatory response of LPS-induced RAW264.7 cells, the nitrite concentration in the culture was measured.

RAW264.7 cells were dispensed into 24-well plates at a concentration of $6 \times 10^{4}$ cells/well and incubated 20 hours before in a $5 \% \mathrm{CO}_{2}$ incubator.

Then paulownia extract was treated with 0,50 , $100,200 \mu \mathrm{g} / \mathrm{mL}$. After one hour, $100 \mathrm{ng} / \mathrm{mL}$ of LPS was treated and then incubated for 18 hours.

The supernatant of the culture solution and Griess reagent were mixed 1: 1 and reacted at room temperature for 10 minutes, and the absorbance was measured at $540 \mathrm{~nm}$ using a microplate reader.

Sodium nitrite $\left(\mathrm{NaNO}_{2}\right)$ was used as a standard curve to calculate the amount of NO produced in the cell culture.

\section{Pro-inflammatory cytokines secretion measurement}

The secretion of IL- 6 and TNF- $\alpha$ cytokine in cell culture medium of RAW 264.7 cells was measured using an ELISA kit (BD Biosciences, San Diego, CA, USA). The method is as follows.

RAW264.7 cells were dispensed in 24-well plates at a concentration of $6 \times 10^{4}$ cells/well and precultured for 18 hours. Then paulownia extract was treated to a concentration of $50,100,200 \mu$ $\mathrm{g} / \mathrm{mL}$ and after one hour was treated with 100 $\mathrm{ng} / \mathrm{mL}$ LPS. The supernatant was recovered after 18 hours of incubation. The IL-6, TNF- $\alpha$ capture antibody was diluted in the coating buffer on the microplate and coated overnight at $4{ }^{\circ} \mathrm{C}$.

After washing with PBS-T containing 0.05\% Tween 20 and blocked with 10\% FBS solution. After washing with PBS-T, the cell culture supernatant was added to each microplate well and reacted for 2 hours at room temperature .

After the reaction, washed with PBS-T, diluted biotinylated anti-mouse IL-6, TNF- $\alpha$ detection antibody was added and reacted for 1 hour. Then streptavidin horseradish peroxidase conjugate was 
added and reacted for 30 minutes. After the reaction, it was washed again with PBS-T and the reaction was carried out in the dark for 30 minutes at room temperature by the addition of Substrate solution. After the reaction was terminated with $2 \mathrm{~N} \mathrm{H}_{2} \mathrm{SO}_{4}$, the absorbance was measured at $450 \mathrm{~nm}$ using a microplate reader.

\section{Inflammation-related protein expression analysis}

To investigate the effect of paulownia extract on inflammation-related protein expression, RAW 264.7 cells were cultured in 6 well plates at a concentration of $1 \times 10^{6}$ cells/well and cultured 18 hours ago. Paulownia extract was pretreated for one hour and then treated with LPS.

After culturing, the cells were collected and washed with PBS (phosphate buffered saline), lysis buffer was added, lysis was performed at $4^{\circ} \mathrm{C}$ for 15 minutes, and the protein was recovered after centrifugation at 13,000 rpm for 15 minutes. Proteins were quantified by Bradford protein assay method, and the quantified proteins were separated by $10-12 \%$ SDS-PAGE in an amount of 15-20 $\mu$ l. The isolated protein was transferred to a polyvinylidene difluoride (PVDF) membrane (GE Healthcare Life Science, Pittsburgh, PA, USA) for 2 hours, and blocked for 1 hour at room temperature with tris buffered saline with tween 20(TBS-T) solution containing 5\% skim milk. Antibodies for examining the expression levels of iNOS, COX-2 and MAPK were diluted 1: 1,000 with anti-mouse iNOS, COX-2 and MAPK and reacted overnight in refrigeration and then washed three times with TBS-T.

As a secondary antibody, anti-mouse IgG and anti-rabbit IgG conjugated with HRP (horseradish peroxydase) were diluted 1: 1,000 and reacted at room temperature for 1 hour. After washing three times with TBS-T and reacting with ECL substrate for 1-3 minutes, each protein band was visualized using an image analyzer (Davinch -Western ${ }^{\mathrm{TM}}$, Youngwha Scientific Co., Seoul, Korea).

\section{Nucleoprotein Extraction}

In order to confirm the expression level of NF$\kappa \mathrm{B}$ p65, RAW264.7 cells were pretreated with paulownia extract for one hour, and then treated with LPS for 15 minutes, and then nuclear proteins were isolated.

Nuclear and cytoplasmic extraction was performed using a NE-PER Nuclear Protein extraction kit (Thermo Scientific, Rockford, IL, USA), and the protein was quantified by the Bradford protein assay method.

\section{Statistical analysis}

The experimental results were obtained by the mean \pm standard deviation (SD) according to each item, and the significance of each group was verified using GraphPad Prism 5.0 version (GraphPad Software, La Jolla, CA, USA).

One-way ANOVA was performed, and post-test was carried out by Tukey's and Dunnett's test methods. It was determined that the $\mathrm{P}$ value was less than 0.05 .

\section{Results and Discussion}

\section{Extraction Yield and Total Polyphenols and Flavonoid Contents of Paulownia}

As a result of measuring the yield of paulownia extract, it was $1.086 \%$ (Table 1). The results of total polyphenol and total flavonoid content, 
which influence the physiological activity of paulownia extract, are shown in Table 1.

The total polyphenol content of Paulownia extract was $143.98 \pm 1.84 \mathrm{mg} \mathrm{GAE} / \mathrm{g}$ extract and the total flavonoid content was $115.33 \pm 4.16 \mathrm{mg}$ $\mathrm{CE} / \mathrm{g}$ extract.

\section{DPPH radical scavenging activity using ESR}

Table 2 shows the results of measuring DPPH radical scavenging activity of paulownia extract using ESR.

Paulownia extract showed $\mathrm{IC}_{50}$ value of $50 \%$ scavenging activity concentration of DPPH radical and showed high DPPH radical scavenging activity at $0.025 \pm 0.001 \mathrm{mg} / \mathrm{mL}$. The $\mathrm{IC}_{50}$ value of vitamin $\mathrm{C}$ used as a positive control was $0.003 \pm$ $0.001 \mathrm{mg} / \mathrm{mL}$, indicating lower radical scavenging activity than vitamin $\mathrm{C}$.

\section{Total Antioxidant Activity Using ABTS Radicals}

The ABTS radical scavenging activity of Paulownia extract is shown in Table 3. Using Trolox as a standard, total antioxidant capacity using ABTS radicals was expressed as TEAC
Table 2. DPPH radical scavenging activity of the PTE by ESR measurement

\begin{tabular}{cc}
\hline Sample & $\begin{array}{c}\text { DPPH radical scavenging activity } \\
(\mathrm{IC} 50, \mathrm{mg} / \mathrm{mL})^{1)}\end{array}$ \\
\hline PTE & $0.025 \pm 0.001$ \\
Vit. C & $0.003 \pm 0.002$ \\
\hline${ }^{1)}$ Values represent means \pm SD $(\mathrm{n}=3)$
\end{tabular}

(mM Trolox eq./mg extract).

The TEAC value of the paulownia extract was $0.821 \pm 0.013$ and the TEAC value of the positive control butylated hydroxytoluene (BHT) was $1.813 \pm 0.022$.

\section{Total Antioxidant Activity Using FRAP Method}

The FRAP method is one of the frequently used methods to check the antioxidant activity of a sample through its electron donating ability.

As a result of measuring the antioxidant power of paulownia extract by FRAP method, it showed $1.647 \pm 0.018 \mathrm{mM} \mathrm{FeSO}_{4}$ eq./mg extract (Table 3).

The positive control group, BHT, showed a value of $1.363 \pm 0.121 \mathrm{mM} \mathrm{FeSO} 4$ eq./mg extract. This indicates that the paulownia extract has a strong antioxidant power through a higher reducing power than the antioxidant BHT.

Table 1. Extraction yields, total polyphenol and flavonoid contents of the Paulownia tomentosa extract (PTE)

\begin{tabular}{cccc}
\hline Sample & $\begin{array}{c}\text { Extraction yields } \\
(\% \mathrm{w} / \mathrm{w})\end{array}$ & $\begin{array}{c}\text { Total polyphenol content } \\
(\mathrm{mg} \mathrm{GAE} / \mathrm{g} \text { extract })^{1)}\end{array}$ & $\begin{array}{c}\text { Total flavonoid content } \\
(\mathrm{mg} \mathrm{CE} / \mathrm{g} \mathrm{extract})^{1)}\end{array}$ \\
\hline PTE & 1.086 & $148.98 \pm 1.84$ & $115.33 \pm 4.16$ \\
\hline
\end{tabular}

GAE (gallic acid equivalents), CE (catechin equivalents). ${ }^{1}$ Values represent means $\pm S D(n=3)$.

Table 3. ABTS radical scavenging and FRAP value of the Paulownia tomentosa extract (PTE)

\begin{tabular}{ccc}
\hline Sample & $\begin{array}{c}\text { TEAC value } \\
(\mathrm{mM} \text { Trolox eq./mg extract })^{1)}\end{array}$ & $\begin{array}{c}\text { FRAP value } \\
(\mathrm{mM} \text { FeSO4 eq./mg extract) })^{1)}\end{array}$ \\
\hline PTE & $0.821 \pm 0.013$ & $1.647 \pm 0.018$ \\
BHT & $1.813 \pm 0.022$ & $1.363 \pm 0.121$ \\
\hline
\end{tabular}

TEAC (Trolox equivalent antioxidant capacity), FRAP (Ferric reducing antioxidant power). "'Values represent means $\pm S D(n=3)$. 

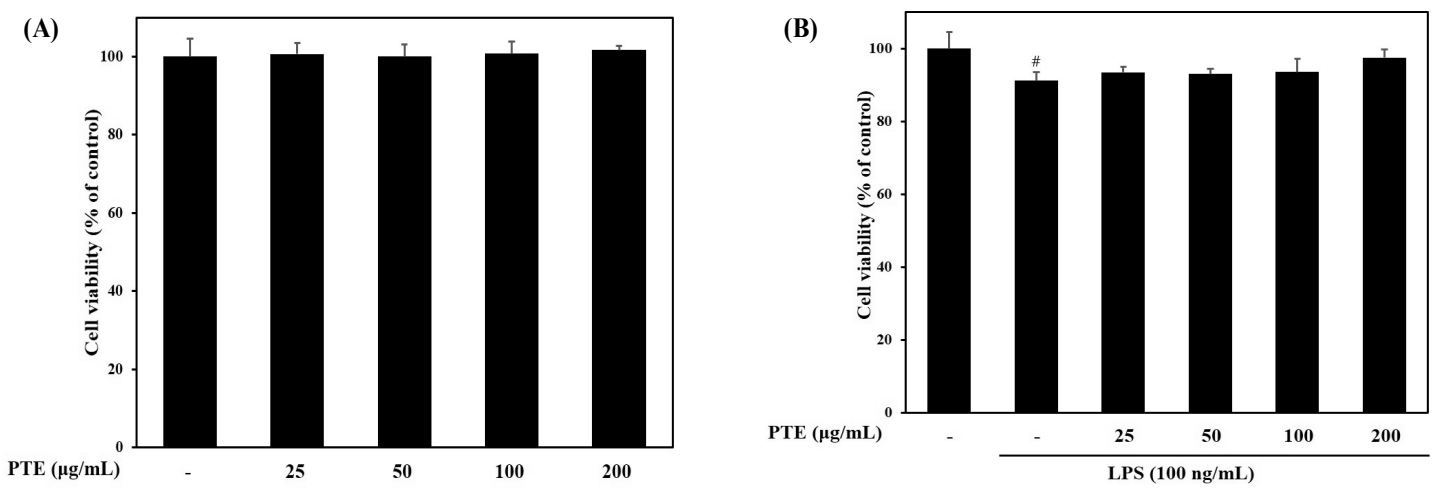

Fig. 1. Effect of Paulownia tomentosa extract (PTE) on cell viability of RAW264.7 cells. RAW264. cells pre-treated with various concentrations of PTE for $24 \mathrm{~h}$, cell viability analyzed by MTT assay.

\section{Cytotoxicity measurement}

Cytotoxicity was examined to determine the effect of paulownia extract on RAW264.7 cells. Paulownia extract was treated at various concentrations $(25,50,100,200 \mu \mathrm{g} / \mathrm{mL})$ and cell viability was measured.

Samples were pretreated an hour ago and cell viability after 24 hours treatment with LPS (100 $\mathrm{ng} / \mathrm{mL}$ ) was measured using MTT assay.

As a result, it was confirmed that there was no significant difference between the control and the cell viability after only treatment with the paulownia extract up to the concentration of 25-200 $\mu \mathrm{g} / \mathrm{mL}$ (Fig. 1A).

In addition, LPS-treated group showed $92.19 \pm$ $2.34 \%$ cell viability compared to the control group. However, the cell survival rate after pretreatment of the extract for one hour and LPS treatment did not show any significant difference. There was no significant difference from the control group not treated with LPS (Fig. 1B).

Therefore, Paulownia extract did not affect cell viability at concentrations of $200 \mu \mathrm{g} / \mathrm{mL}$ or less, and thus was determined to be non-toxic. Then the experiment was carried out at a concentration of $200 \mu \mathrm{g} / \mathrm{mL}$ or less.

\section{Inhibitory Effect of Nitric Oxide (NO) Formation}

In this study, the effect of paulownia extract on NO production was examined. After 1 hour pretreatment of paulownia extract, NO production in RAW264.7 cells induced inflammatory reaction with LPS was measured using griess reagent.

It was measured at concentrations of extracts (50, 100, $200 \mu \mathrm{g} / \mathrm{mL})$ that did not affect cell viability. When LPS was treated to induce inflammation, NO production was $36.08 \pm 0.11 \mu$ M. When treated with $200 \mu \mathrm{g} / \mathrm{mL}$ Paulownia extract, NO production was $21.379 \pm 0.11 \mu \mathrm{M}$. This is about $40 \%$ NO production inhibitory effect (Fig. 2).

The results of this study indicate that paulownia extract inhibits NO production in a concentration-dependent manner which increased in LPS induced macrophages.

\section{Inhibitory Effect of Pro-inflammatory Cytokines Production}




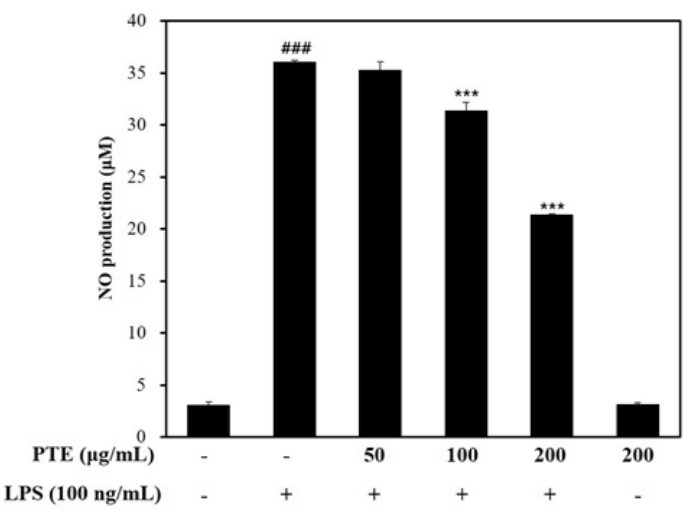

Fig. 2. Inhibitory effect of Paulownia tomentosa extract (PTE) on NO production in LPS-stimulated RAW 264.7 cells. RAW264.7 cells were treated with PTE as indicated dose, then stimulated with LPS $(100 \mathrm{ng} / \mathrm{mL})$ for $18 \mathrm{~h}$. NO production in supernatant was measured uing Griess reagent. ${ }^{\# \#} P<0.001$ vs. control group, ${ }^{* * *} P<0.001$ vs. LPS group.

To investigate the effect of paulownia extract on cytokine secretion in LPS-induced inflammatory response RAW 264.7 cells, Paulownia extract was pretreated at various concentrations to measure changes in secretion levels of IL-6 and TNF- $\alpha$

(A)

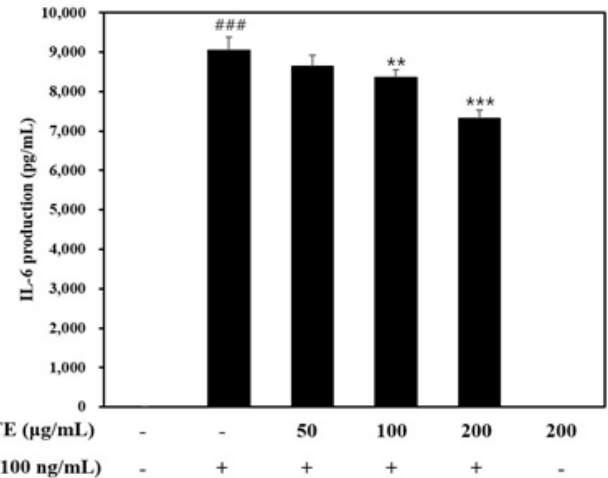

using the ELISA kit.

As a result, it was confirmed that the secretion of cytokine increased by LPS was inhibited by paulownia extract (Fig. 3).

In the case of IL-6(Fig. 3A), the amount of secretion increased to $9037.77 \pm 347.30 \mathrm{pg} / \mathrm{mL}$ by LPS was suppressed to $7311.85 \pm 224.80$ $\mathrm{pg} / \mathrm{mL}$ when treated with $200 \mu \mathrm{g} / \mathrm{mL}$ Paulownia extract. This can be understood as an inhibitory effect of about $20 \%$.

When inflammation was induced by LPS treatment, TNF- $\alpha$ showed a secretion amount of $460.18 \pm 22.62 \mathrm{pg} / \mathrm{mL}$. In comparison, in the group treated with $200 \mu \mathrm{g} / \mathrm{mL}$ Paulownia extract, the secretion was $391.13 \pm 25.35 \mathrm{pg} / \mathrm{mL}$, which was suppressed by $15 \%$ (Fig. 3B).

Through this, paulownia extract treatment seems to reduce of pro-inflammatory cytokines conentrations dependently.

\section{Inhibitory Effect of Inflammation-related Protein Expression}

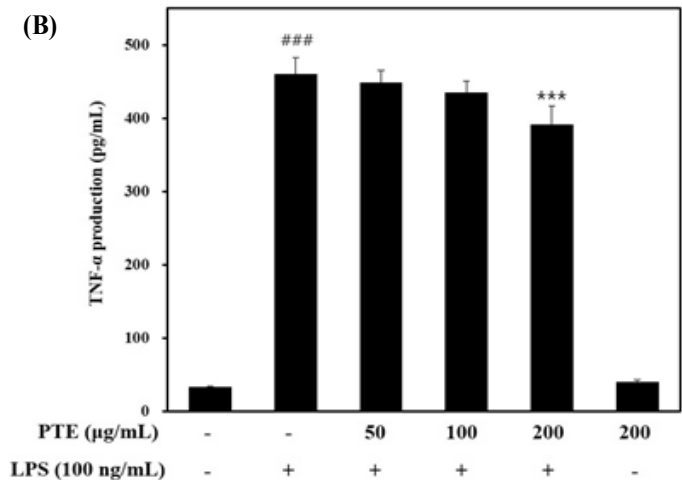

Fig. 3. Effect of Paulownia tomentosa extract (PTE) on LPS-induced cytokine production. RAW264.7 cells were treated with PTE as indicated dose, then stimulated with LPS $(100 \mathrm{ng} / \mathrm{mL})$ for $18 \mathrm{~h}$. The supernants were harvested and pro-inflammatory cytokine (IL-6 (A) and TNF- $\alpha(B))$ levels were measured by ELISA as described in Method. The values are means \pm S.D. of three independent experiments. ${ }^{\# \#} P<0.001$ vs. control group, ${ }^{* *} P<0.01$ and ${ }^{* * *} P<0.001$ vs. LPS group. 
Western blot analysis was performed to investigate whether paulownia extracts influence the expression regulation of iNOS and COX-2. In the LPS-treated group, iNOS and COX-2 protein expression was significantly increased compared to the control group (Fig. 4).

In the group treated with paulownia extract, iNOS expression was reduced in a concentration -dependent manner and did not affect the expression inhibition of COX-2.

Signal transduction pathways of MAPKs (ERK, JNK, p38) play an important role in the activation of the inflammatory response. Particularly involved in inducing activation of transcription factors, including NF- $\kappa \mathrm{B}$ and activator protein 1 (AP-1), increased secretion of inflammation-related mediators $^{16,17)}$.

The effect of paulownia extract on MAPKs expression was examined. LPS treatment significantly increased the expression of MAPK. The expression of p-ERK was markedly increased, but markedly decreased when $200 \mu \mathrm{g} /$ $\mathrm{mL}$ of Paulownia extract was treated. However, p-p38 and p-JNK were not affected (Fig. 5). As a

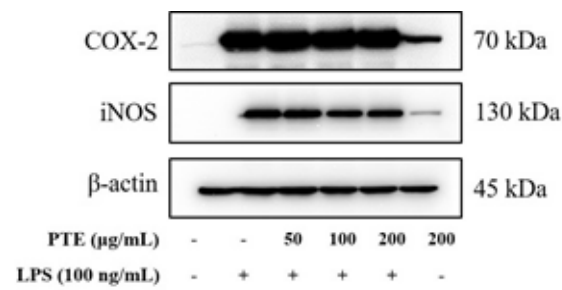

Fig. 4. Effect of Paulownia tomentosa extract (PTE) on COX-2, iNOS expression in LPS-stimulated RAW264.7 cells. RAW264.7 cells were pre-treated with PTE as indicated dose, then stimulated with LPS (100 ng/mL) for $18 \mathrm{~h}$ (iNOS, COX-2). Expressions of protein were determined by western blot analysis using specific antibodies. The $\beta$-actin was used as a loading control. result of measuring the change in TBK1, a protein that affects MyD88 independent signaling, paulownia extract did not affect the increased p-TBK1 after LPS treatment (Fig. 5).

$\mathrm{NF}-\kappa \mathrm{B}$ is a transcriptional regulator that induces expression of inflammation-related mediators. When activated by LPS, NF- $\kappa \mathrm{B}$ increases the expression of iNOS, COX-2, and pro-inflammatory cytokine $^{18)}$.

Normally, cells are present in the cytosol in the heterodimer form of NF- $\kappa \mathrm{B}$ p65 and $\mathrm{p} 50$. When $\mathrm{I} \kappa \mathrm{B} \alpha$ is phosphorylated by the inflammatory response, it moves to the nucleus and acts as a transcription factor ${ }^{19)}$.

In this study, $\mathrm{p}-\mathrm{I} \kappa \mathrm{B} \alpha$ was significantly increased and the amount of $\mathrm{I}_{\kappa} \mathrm{B} \alpha$ was significantly decreased in the LPS-induced group (Fig. 6).

However, when the paulownia extract was treated, it was confirmed that the phosphorylation of $\mathrm{I} \kappa \mathrm{B} \alpha$ was inhibited. In addition, the expression of $\mathrm{NF}-\kappa \mathrm{B}$ p65 protein in the nuclear fraction showed that in the LPS-treated group, the

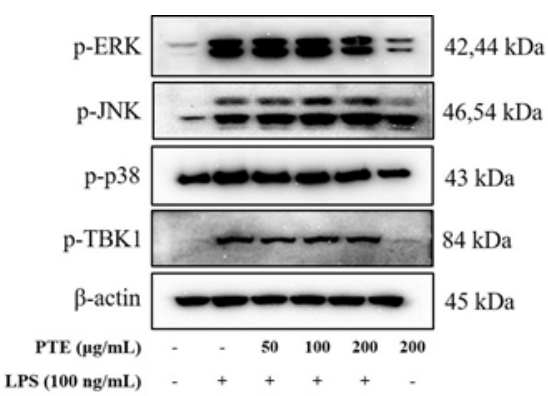

Fig. 5. Effect of Paulownia tomentosa extract (PTE) on MAPK and TBK1 expression in LPS-stimulated RAW264.7 cells. RAW264.7 cells were pre-treated with PTE as indicated dose, then stimulated with LPS $(100 \mathrm{ng} / \mathrm{mL})$ for $30 \mathrm{~min}$. Expressions of protein were determined by western blot analysis using specific antibodies. The $\beta$-actin was used as a loading control. 


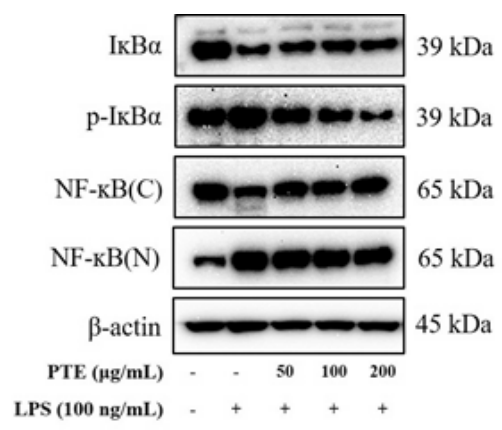

Fig. 6. Effect of Paulownia tomentosa extract (PTE) on NF- $K$ B pathway in LPS-stimulated RAW264.7 cells. RAW 264.7 cells pre-treated with a various concentration of PTE for $1 \mathrm{~h}$ and stimulated with LPS $(100 \mathrm{ng} / \mathrm{mL})$ for $15 \mathrm{~min}$. Nuclear (N) and cytoplasmic proteins $(\mathrm{C})$ were isolated and examined for $\mathrm{NF}-K \mathrm{~B}$ using western blot analysis. The $\beta$-actin was used as a loading control.

intranuclear migration of NF- $\kappa \mathrm{B}$ was significantly increased in comparison with the control group and decreased in the paulownia extract-treated group (Fig. 6).
As a result, it was confirmed that the paulownia extract has anti-inflammatory effect by inhibiting the phosphorylation of $\mathrm{I} \kappa \mathrm{B} \alpha$ in LPS-activated macrophages, inactivating signaling pathways that inhibit the migration of $\mathrm{NF}-\kappa \mathrm{B}$ p65 in the nucleus. Therefore, based on the results of this study, the MyD88 dependent pathway schema related to the anti-inflammatory efficacy of paulownia extract is shown in Fig.7.

\section{Summary}

The purpose of this study was to determine the antioxidant activity of paulownia extract and to determine the total polyphenol and flavonoid content in paulownia extract. The total polyphenol content was $148.98 \pm 1.84 \mathrm{mg} \mathrm{GAE} / \mathrm{g}$ extract and the total flavonoid content was $115.33 \pm 4.16 \mathrm{mg}$ $\mathrm{CE} / \mathrm{g}$ extract.

As a result of measuring DPPH radical

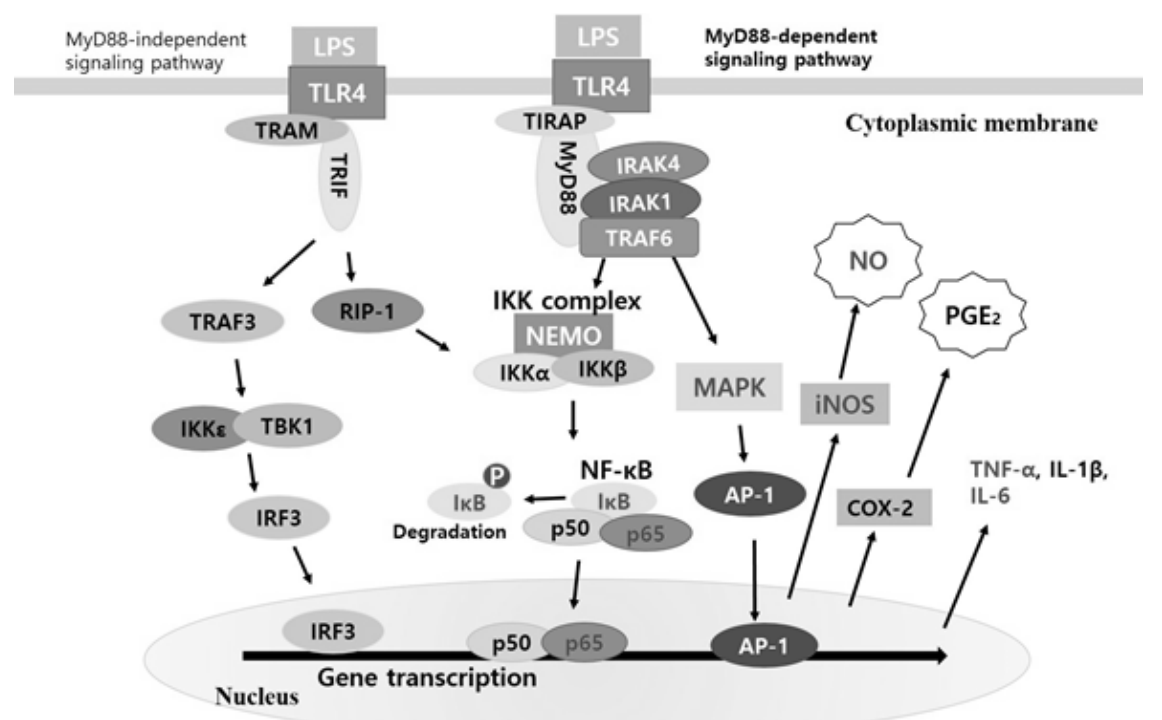

Fig. 7. Effect of Paulownia tomentosa extract (PTE) on MyD88 dependent signaling pathway in LPS-stimulated RAW264.7 cells. 
scavenging ability using $\mathrm{ESR}$, the $\mathrm{IC}_{50}$ value of $50 \%$ radical scavenging concentration was 0.025 $\mathrm{mg} / \mathrm{mL}$, indicating high DPPH radical scavenging activity.

Radical scavenging activity using ABTS and total antioxidant activity using FRAP method also showed that Paulownia extract had high antioxidant effect. RAW264.7 cells induced inflammation with LPS were treated with paulownia extract at non-toxic concentrations to determine $\mathrm{NO}$, an inflammatory mediator. As a result, it was confirmed that the amount of NO produced was reduced in a concentration -dependent manner.

In addition, the production of pro-inflammatory cytokine (IL-6, TNF- $\alpha$ ) was inhibited, iNOS expression was also reduced.

Paulownia extract also affected the phosphorylation of ERK through the MyD88 dependent signal transduction pathway, a major pathway of the inflammatory response. In addition, the inhibition of phosphorylation of $\mathrm{I} \kappa \mathrm{B}$ $\alpha$ inhibited nuclear migration of $\mathrm{NF}-\kappa \mathrm{B}$, which showed an anti-inflammatory effect.

The results of this study can provide basic information on anti-inflammatory materials derived from Korean native plants. Further studies on the separation and purification of active compounds with anti-inflammatory effects are expected.

\section{Acknowledgement}

This paper was supported by the semyung University Research Grant of 2019

\section{References}

1. Kryston TB, Georgiev AB, Pissis P. Georgakilas AG. Role of oxidative stress and DNA damage in human carcinogenesis. Mutation Research Fundamental and Molecular Mechanisms of Mutagenesis 2011;711(1):193-201.

2. White PAS, Oliveira RCM, Oliveira AP, Serafini MR, Araujo AAS, Gelain DP et al. Antioxidant Activity and Mechanism of Action of Natural Compounds Isolated from Lichens: A Systematic Review. Molecules 2014;19:14496-527.

3. Brewer, MS. Natural Antioxidants: Sources, Compounds, Mechanism of Action, and Potential Applications. Compr Rev Food Sci Food Saf 2011;10:221-47.

4. Eun CS, Hwang EY, Lee SO, Yang SA, Yu MH. Anti-oxidant and Anti-inflammatory Activities of Barley Sprout Extract. J Life Science 2016;26(5):537-44.

5. Kim KA, Yi HS, Yun HJ, Park SD. Anti-oxidative and Anti-inflammatory Effect of Fractionated Extracts of Cynomorium Songaricum. Korean J Orient Physiology \& Pathology 2009;23(6):1320-31.

6. Yamauchi T, Date H, Saihara Y, Osada K. Deodorants Containing Hydrogen Peroxide and Plant Extracts. Jpn. Kokai Takkyo koho JP; 1987. p.62-357.

7. Kim MS, Lee DC, Hong JE, Chang IS, Cho HY, Kwon YK, Kim HY. Antimicrobial Effects of Ethanol Extracts from Korean and Indonesian Plants. Korean Journal of Food Science and Technology 2000;32(4):949-958.

8. Park YM, Jang SK, Kim YS, Kim BK. The constituents of Paulwnia stem. Yakhak Hoeji 1991;31:301-307.

9. Jun BS, Cha JY, Cho YS. Antioxidative Activities of Fruit Extracts of Paulownia tomentosa Stued. Korean J. Food Preserv 2001;8(2):231-238. 
10. Singleton VL, Rossi JAJ. Colorimetry of total phenolics with phosphomolybdic-phosphotungstic acid reagents. Am. J. Enol. Viticult. 16: 144-158 (1965)

11. Jia Z, Tang M, Wu J. 1999. The determination of flavonoid content in mulberry and their scavenging effects on superoxide radicals. Food Chem 64: 555-559.

12. Lee SJ, Kim EK, Hwang JW, Oh HJ, Yang SI, Lee SJ, Jeon BT, Kim SK, Park PJ. 2009. Free radical scavenging activity of $\beta$ -chitooligosaccharides. $J$ Chitin Chitosan 14: 24-28.

13. Re R, Pellegrini N, Proteggente A, Pannala A, Yang M, Rice-Evans C. 1999. Antioxidant activity applying an improved ABTS radical cation decolorization assay. Free Radic Biol Med 26: 1231-1237.

14. Benzie IF, Strain JJ. The ferric reducing ability of plasma (FRAP) as a measure of "antioxidant power": The FRAP assay. Anal. Biochem. 239: 70-76 (1996)

15. Berridge MV, Tan AS (1993) Characterization of the cellular reduction of 3-(4,5-dimethylthiazol -2yl)-2,5-diphenyltetrazolium bromide (MTT) : subcellular localization, substrate dependence, and involvement of mitochondrial electron transport in MTT reduction. Arch Biochem
Biophys, 303, 474-482.

16. Schnyder-Candrian, S., V. F. Quesniaux, F. Di Padova, I. Maillet, N. Noulin, I. Couillin, R. Moser, F. Erard, B. B. Vargaftig, B. Ryffel, and B. Schnyder (2005) Dual effects of p38 MAPK on TNFdependent bronchoc onstriction and TNF-independent neutrophil recruitment in lipopolysaccharide-induced acute respiratory distress syndrome. J. Immunol. 175: 262-269.

17. Zhong, J. and J. M. Kyriakis (2007) Dissection of a signaling pathway by which pathogen -associated molecular patterns recruit the JNK and p38 MAPKs and trigger cytokine release. J. Biol. Chem. 282: 24246-24254

18. Hawiger, J. (2001) Innate immunity and inflammation: A transcriptional paradigm. Immunol. Res. 23: 99-109.

19. Nam, N. H. (2006) Naturally occurring NF- $\kappa$ B inhibitors. Mini Rev. Med. Chem. 6: 945-951.

\section{ORCID}

Na-Young JO https://orcid.org/0000-0003-2802-2626

Ki-Tae Kim https://orcid.org/0000-0003-4892-3472 